Revista de Ciencias Sociales - Número 64 (2014) - Páginas 169-204

La pareja del mismo sexo y su protección por el derecho de la familia en Francia

\title{
LA PAREJA DEL MISMO SEXO Y SU PROTECCIÓN POR EL DERECHO DE LA FAMILIA EN FRANCIA
}

\section{THE SAME-SEX PARTNER AND THE PROTECTION BY FAMILY LAW IN FRANCE}

\author{
PABLO CORNEJO AGUILERA* \\ Departamento de Derecho Privado, Facultad de Derecho \\ Universidad de Chile \\ pabloandres.cornejoaguilera@unil.ch
}

\section{Resumen}

El pasado 17 de mayo de 2013 se aprobó en Francia la Ley $\mathrm{N}^{\circ}$ 2013-404, que abre el matrimonio a las parejas del mismo sexo, en lo que se vislumbra puede constituir un hito en la discusión cuyo impacto trascienda las fronteras de ese ordenamiento, atendida la influencia cultural que todavía conserva el país, particularmente en la doctrina latinoamericana y chilena. Sin embargo, la obtención de este importante logro puede resultar sorprendente, sobre si consideramos que, hasta una fecha tan reciente como 1997, las parejas del mismo sexo en Francia se encontraban desprovistas de

* Abogado. Licenciado en Ciencias Jurídicas y Sociales, Universidad de Chile.

Becario gobierno suizo para estudios de postgrado. Actualmente cursando Master, Droit international et comparé, Universidad de Lausanne. Las traducciones son libres y han sido realizadas por el autor. Mis agradecimientos a la profesora María José Arancibia Obrador por sus valiosos comentarios y su ayuda en la edición de este artículo. Artículo recibido el 7 de noviembre de 2013 y aceptado el 6 de enero de 2014.

Revista de Ciencias Sociales - Número 64 (2014) - Universidad de Valparáíso - ISSN 0716-7725-Valparaíso, Chile 
cualquier reconocimiento o protección jurídica. En el presente trabajo se expondrá de una manera sucinta el proceso de reforma que experimentó la legislación francesa para llegar al mariage pour tous, relacionándolo con un proceso de más largo alcance, como fue aquel desencadenado durante los años sesenta y cuya finalidad fue actualizar el Derecho de la familia, a fin de proveer de una respuesta a las demandas de igualdad entre hombres y mujeres que se produjeron como consecuencia de los cambios sociales.

\title{
Palabras claves
}

Derecho de Familia, Homosexualidad, Matrimonio, Unión Civil, Concubinato.

\begin{abstract}
On last May 17, 2013 Law No. 2013-404 was approved in France. This law opened marriage to same-sex couples, that is seen as a milestone in the discussion which impact transcends the boundaries of that system, considering the cultural influence that still retains the country, particularly in the Latin American and Chilean doctrine. However, the obtaining of this important achievement may become surprising, considering that, until as recently as 1997, same-sex couples in France were devoid of any recognition or legal protection. In this paper, we will succinctly expose the reform process experienced by French law to reach the mariage pour tous, relating it to a longer range process, as it was the one triggered during the sixties and whose purpose was to update the law family in order to provide a response to the demands of equality that occurred as a result of social changes.
\end{abstract}

\section{Keywords}

Family Law, Homosexuality, Marriage, Civil Union, Cohabitation.

\section{Introducción}

De la misma manera como ha ocurrido en otros ordenamientos jurídicos occidentales, el Derecho de la familia en Francia ha sufrido grandes transformaciones, que han cambiado completamente la fisonomía que presentaba esta institución en el Código de 1804. En efecto, la antigua regulación familiar contenida en el Código, inspirada en la protección de la familia legítima fundada en el matrimonio,

Facultad de Derecho y Ciencias Sociales - Universidad de Valparaíso - Chile 
contrato de "género", no igualitario y jerárquico ${ }^{1}$, que confería una posición de primacía al marido, "naturalmente" designado para guiar a la familia y quien detentaba un "poder" marital y parental (la puissance maritale y parentale) sobre la mujer y sus hijos, respectivamente, ha experimentado profundas reformas, las cuales se han centrado en la búsqueda de una verdadera igualdad entre los cónyuges y en la promoción del interés de los hijos. De esta forma, se puede constatar la existencia de un proceso de transformación profundizado a partir de la década de 1960, bajo la guía del Decano Jean Carbonnier, que paulatinamente fue modificando cada una de las instituciones que pertenecen a esta rama del Derecho ${ }^{2}$, proceso cuyo éxito es atribuible en gran medida a su incorporación en el Código civil y a su unidad de inspiración, según ha señalado el profesor Cabrillac ${ }^{3}$.

Sin embargo, esta primera etapa se relacionó propiamente con la igualdad de las relaciones entre marido y mujer ${ }^{4}$ y con la importancia de la protección de los hijos ${ }^{5}$, sin afectar la posición jurídica de la pareja

1. THÉRY, Irene: Couple, filiation et parenté aujourd'hui. Le droit aux mutations de la famille et de la vie privé. París: Editions Odile Jacob. 1998. Pág. 27.

2. De una manera somera, se pueden señalar como grandes hitos en este proceso la reforma de la situación jurídica de los incapaces menores de edad (1964), de los regímenes matrimoniales (1965 y 1985), de la adopción (1966 y 1976), de la situación jurídica de los incapaces mayores de edad (1968), de la autoridad parental (1970, 1987, 1993, 1996 y 2002), de la fíliación (1972), del divorcio (1975 y 2004) y de la ausencia (1977).

3. CABRILLAC, Rémy: Introduction générale au Droit. $7^{\circ}$ edición. París: Dalloz. 2007. Pág. 54.

4. Donde la mujer, al decir de THÉRY, es vista cada vez más como una plena interlocutora del marido en el contexto del matrimonio, cuestión que se refleja en la codirección de la familia que nace como consecuencia de la reforma de la autoridad parental de 1970 y que es confirmada por la importancia que tiene la renovación continua de la decisión de permanecer juntos, a partir de la introducción en 1975 del divorcio por consentimiento mutuo. THÉRY, Irene. Ob. cit. Págs. 30-31.

5. Hasta el punto que es posible decir que el otrora carácter necesario de la indisolubilidad del matrimonio, terminó por trasladarse a la relación paternofilial.

Revista de Ciencias Sociales - Número 64 (2014) - Universidad de Valparáiso - ISSN 0716-7725-Valparáís, Chile 
que desarrolla una vida en común sin estar casada, en lo que concierne propiamente a las consecuencias del desarrollo de este proyecto ${ }^{6}$. En este sentido, si bien el legislador reconoció ciertos derechos a los concubinos, debe destacarse que lo hizo a través de una normativa que siempre se caracterizó por su carácter especial y fragmentario: para la existencia de un verdadero estatuto de pareja, alternativo al matrimonio, habría que esperar hasta el 15 de noviembre de 1999, fecha en la cual será promulgada la Ley $\mathrm{N}^{\circ}$ 99-944, que introdujo la figura del pacto civil de solidaridad (en adelante, pacs) y que además incorporó una definición general de concubinato ${ }^{7}$.

En forma paralela al desarrollo de este proceso de renovación de la legislación familiar, otra transformación se produjo en el plano más general de las relaciones sociales, la cual viene en gran medida a definir el sentido y alcance de la primera: a partir de los años sesenta, las sociedades occidentales (y dentro de ellas, la francesa) han experimentado una revolución en la manera como son concebidas las relaciones afectivas y sexuales. En efecto, la oportunidad que proporcionaron los progresos de la ciencia médica, que permitieron controlar por primera vez las consecuencias de la actividad sexual, gracias a los métodos anticonceptivos ${ }^{8}$, contribuyó a separar la otrora necesaria

6. Debemos destacar en este punto que, por vía de conferir un reconocimiento a

la paternidad desarrollada fuera del marco de la relación matrimonial, el Derecho francés ya había conferido, de manera indirecta, una primera protección a la pareja no casada. En este sentido, como destaca THÉRY “hoy, las familias naturales existen en el Derecho, y los hijos son masivamente reconocidos por sus dos padres, que viven en pareja. Si la familia legítima permanece como el modelo dominante, se advierte un aumento importante de las familias naturales en todas las clases sociales. En 1995, 37,6\% de los niños nacen de padres no casados". THÉRY, Irene. Ob. cit., pág. 43.

7. Esta regulación sufrirá modificaciones, a través de la Ley $\mathrm{N}^{\circ}$ 2006-728, de 23 de junio de 2006, y de la Ley $\mathrm{N}^{\circ} 2007-1223$, de 21 de agosto de 2007.

8. Sobre la regulación de los métodos anticonceptivos en Francia, puede revisarse la interesante descripción realizada por el profesor Borrillo. Según señala este autor, durante un largo periodo de tiempo estas prácticas estuvieron prohibidas en Francia. Una ley de 1920 sancionaba a toda persona que describa, divulgue u ofrezca revelar procedimientos destinados propiamente a prevenir el embarazo, o incluso a facilitar el uso de estos procedimientos. Por el contrario, solamente resultaban

Facultad de Derecho y Ciencias Sociales - Universidad de Valparaíso - Chile 
relación entre sexo y procreación, cuestión que terminó por afectar incluso la función tradicionalmente atribuida al matrimonio en cuanto marco de ejercicio lícito de la sexualidad ${ }^{9}$. En este sentido, resultan muy ilustrativas las palabras del profesor Borrillo, quien ha destacado que:

Si bien las relaciones sexuales reproductivas han sido extremadamente minoritarias, la asociación entre sexualidad y reproducción no ha abandonado jamás el imaginario popular. Así, la finalidad reproductiva ha permitido tradicionalmente justificar la actividad sexual, tolerada únicamente en ese contexto [...] Esta disociación entre sexualidad y reproducción, gracias a los diversos procesos que venimos de describir, ha producido una verdadera revolución, en primer lugar para las mujeres que no sufren más un embarazo no deseado, mas también para los homosexuales toda vez que la reproducción dejará de ser considerado el elemento legitimador de la sexualidad ${ }^{10}$.

admisibles los métodos "naturales". Si bien en 1961 se abre en Grenoble el primer centro de planificación familiar, debió esperarse hasta 1967 para que la prohibición de la anticoncepción conozca su fin (a excepción de lo que se refiere a su acceso para menores de edad). Sin embargo, la publicidad de estos métodos solamente sería admitida a partir de 1987, fecha a contar de la cual podían promocionarse los preservativos, pero solamente a condición de presentarlos como una herramienta de protección contra las enfermedades de transmisión sexual y no como un método anticonceptivo. Treinta y un años debieron pasar entre la primera ley y la autorización plena de la anticoncepción, lo cual se obtendrá gracias a la Ley $\mathrm{N}^{\circ}$ 91-73 de 18 de enero de 1998, la cual permite la publicidad del preservativo como método anticonceptivo. Sin embargo, esta situación contrasta con el hecho que desde 1974 el acceso a ciertos métodos anticonceptivos sea gratuita. Finalmente, una ley de 13 de diciembre de 2000 permite a una mujer menor de edad acceder a los métodos anticonceptivos de urgencia, sin autorización de sus padres. BORRILLO, Daniel: Le Droit des sexualités. París: PUF., 2009. Págs. 60-61.

9. Como destaca la profesora THÉRY "la división del mundo impuesta por el antiguo 'contrato de género', que oponía las madres de familia y las rameras, la parte honesta de la parte vergonzosa del ser humano, no autorizaba la sexualidad sino para la procreación y el amor santificado por la familia. La prohibición de los amores adolescentes, la doble moral sexual, la penalización del adulterio, y la condena de la homosexualidad participaban de un orden moral del cual la familia estaba considerado ser su santuario". THÉRY, Irene. Ob. cit., pág. 31.

10. BORRILLO, Daniel. Ob. cit. Pág. 63. 
Como se anticipa en el párrafo transcrito, esta radical transformación en la manera como son concebidas las relaciones afectivas y sexuales tendrá un impacto significativo en la reivindicación de una legitimación pública de las orientaciones sexuales alternativas. La lucha por la igualdad de género, entre el hombre y la mujer, precedió a aquella de las personas homosexuales por la igualdad de las sexualidades, favoreciendo la creación de las condiciones sociales necesarias para la afirmación pública de las personas del mismo sexo ${ }^{11}$. Como ha destacado Vivier, a diferencia de lo que ocurría en otros tiempos, donde el matrimonio se imponía a un hombre y una mujer que querían vivir juntos, quedando fuera de él solamente el concubinato, simple unión de hecho, reprobada hasta fines de los años sesenta por las buenas costumbres, esta época conocerá cuatro fenómenos que no pararán de crecer: el desarrollo del concubinato ${ }^{12}$, el

11. Sin embargo, se puede constatar que las personas homosexuales han tenido un tratamiento generalmente favorable por parte de la legislación francesa. Considerando que la ley no debe regir las costumbres de los ciudadanos en la medida que el orden público no se encuentra comprometido, el Código penal de 1791 no sancionó las relaciones entre individuos del mismo sexo, regulación que va a implicar una modificación importante en comparación con la legislación del Antiguo Régimen. La misma solución será adoptada por el Código penal aprobado bajo Napoleón, en 1810. De esta forma, Francia se convirtió en el primer país europeo en despenalizar la homosexualidad. Sin embargo, esta situación va a durar sólo hasta el gobierno de Vichy: una ley de 6 de agosto de 1942 incorporó una nueva conducta al artículo 334 del Código penal (que reprime la corrupción de la juventud), sancionando el hecho de cometer "uno o más actos impúdicos o contra natura con un menor de su mismo sexo menor de veintiún años". En la misma época, miles de homosexuales fueron enviados a la Alemania nazi, que los hizo llevar un triángulo rosa y los envió a los campos de exterminio. CABALLERO, François: Droit du sexe. París: L.D.G.J. 2010, pág. 277.

12. Como destaca la profesora THÉRY, en los años setenta la cohabitación juvenil aparecía como un "ensayo de matrimonio": dos años después del inicio de la unión, la mitad de ellos contraían matrimonio, $41 \%$ permanecían conviviendo y un $7 \%$ habían terminado. Desde esta época, el matrimonio deja de ser concebido como un signo necesario del compromiso de largo plazo. Entre las parejas formadas fuera del matrimonio en la década de los noventa, un $9 \%$ estaban casados al fin de un año de vida en común, $30 \%$ al término de cinco años, mientras que un $48 \%$ vivían todavía juntos sin casarse al fin de ese mismo término. De esta forma, la convivencia ha devenido una forma de vida en común alternativa al matrimonio. THÉRY, Irene. Ob. cit., pág. 41.

Facultad de Derecho y Ciencias Sociales - Universidad de Valparaíso - Chile 
enrarecimiento de los matrimonios, el aumento del número de divorcios y la aceptación de la homosexualidad ${ }^{13}$.

Sin embargo, como en su oportunidad bien destacó BachIgnasse $^{14}$, la emergencia de la homosexualidad en los años setenta, bajo la forma de un nuevo movimiento social, no condujo inmediatamente a una reconciliación entre la homosexualidad y la familia. Por el contrario, el movimiento homosexual se situó en sus inicios en los prolongamientos de mayo de 1968, compartiendo su puesta en juicio global de las instituciones sociales, en un cuestionamiento que necesariamente comprendió a la familia y el matrimonio. Esta aproximación solamente cambiará durante la década de los ochenta, época en que comenzarán a sentirse las terribles consecuencias humanas y económicas de la epidemia del SIDA, las cuales dejaron en evidencia la situación de precariedad en que quedaba el miembro de la pareja después de la muerte de su compañero. Frente a esta nueva realidad, lentamente los comportamientos y las demandas comienzan a cambiar. Como ha sido destacado por Caballero, los riesgos de contagio por vía sexual hicieron valorar la fidelidad y la estabilidad de la pareja en desmedro del "vagabundaje sexual", lo que a su vez incidió en que las personas homosexuales comiencen a reivindicar los derechos que el ordenamiento reconoce a las parejas estables, nacidos del matrimonio o del concubinato, viéndose enfrentados constantemente a una jurisprudencia que niega la extensión de los derechos civiles y sociales a las parejas gays y lesbianas ${ }^{15}$.

En este contexto, se puede advertir desde los comienzos de los años noventa el inicio de un debate público sobre la conveniencia de conferir a las parejas no casadas (y más específicamente, a las parejas no casadas del mismo sexo) un estatuto familiar propio, que a partir de

13. VIVIER, Jean-Loup: Le pacte civil de solidarité. Un nouveau contrat. París: LHarmattan. 2001. Pág. 8.

14. BACH-IGNASSE, Gérard: "Familles et homosexualités". En: Borrillo, Daniel. Homosexualités et droit. De la tolérance sociale à la reconnaissance juridique. París: PUF. 1998. Págs. 123-124.

15. CABALLERO, François. Ob. cit. Pág. 279.

Revista de Ciencias Sociales - Número 64 (2014) - Universidad de Valparáíso - ISSN 0716-7725-Valparaíso, Chile 
los aspectos patrimoniales pueda proteger a las personas que hayan elegido desarrollar sus vidas juntos, sin contraer matrimonio. Como se verá en la tercera parte de este trabajo, las soluciones propuestas partieron de la base que debía implicar el nacimiento de una nueva institución, de naturaleza contractual y claramente diferenciada del matrimonio. Sin embargo, para comprender los objetivos y los alcances de la nueva regulación, es necesario previamente examinar cuál era la situación de la legislación francesa referida a los concubinos (incluyendo a las parejas del mismo sexo) al momento de la aprobación del pacs.

\section{La legislación y la jurisprudencia francesa anterior a la aprobación del PACS}

De una manera general, es posible advertir una evolución en la manera como el Derecho francés se ocupa del concubinato. Si bien el Código de 1804 adoptó una posición que ha sido calificada de abstencionista $^{16}$ frente a la problemática de las parejas que desarrollan una vida en común sin estar casadas - la cual queda bien reflejada en la frase "Les concubines se passent de la loi, la loi se désintéresse d'eux" tradicionalmente atribuida al propio Napoleón-, cabe destacar que tampoco se consideró el concubinato para efectos de su prohibición, de manera que los concubinos no arriesgaban por esta razón ninguna sanción o pérdida de algún derecho por el hecho de vivir juntos. Se trataba simplemente de una situación de hecho, que en principio no interesaba a la legislación, aunque pronto se dejaron sentir las primeras consecuencias de una doctrina y jurisprudencia que vieron con creciente desconfianza la existencia de estas uniones contrarias a las "buenas costumbres", cuestión que se reflejó en la extensión de la doctrina de la causa ilícita (por inmoralidad) a la donación entre concubinos ${ }^{17}$ y a la

16. Sin embargo, se puede decir, siguiendo a los profesores Malaurie y Fulchiron, que la ignorancia es en sí misma un medio de lucha indirecta contra el concubinato, toda vez que la concubina y sus hijos se encontrarán en una situación de absoluta desprotección. Por esta razón, se puede pensar que la derogación de las diferentes categorías de hijos supone un primer reconocimiento del concubinato. MALAURIE, Philippe y FULCHIRON, Hugues: La famille. $3^{\circ}$ edición. París: Defrénois. 2009. Pág. 157.

17. Como se ha señalado, en la aplicación de los artículos 1131 y 1133 del Código civil, la jurisprudencia ha hecho la distinción entre los casos donde la donación

Facultad de Derecho y Ciencias Sociales - Universidad de Valparaíso - Chile 
designación de un concubino como beneficiario de un contrato de seguro contra daños personales ${ }^{18}$, sobre todo cuando la relación concubinaria tenía un carácter adulterino.

Sin embargo, esta primera posición no pudo ser mantenida por mucho tiempo. Como han destacado los profesores Malaurie y Fulchiron, las situaciones de concubinato producen consecuencias de hecho que la hacen imposible de ignorar, por consideraciones de equidad y también por razones de oportunidad social ${ }^{19}$, sobre todo en un contexto de cambio sobre las concepciones sociales sobre la realidad familiar. Por esta razón, no es de extrañar que se haya producido una evolución en la legislación, donde la ignorancia jurídica del concubinato ha cedido su lugar a textos particulares que confieren a los concubinos determinados derechos, en materia de seguridad social, de arrendamiento, de responsabilidad civil, etc. ${ }^{20}$, si bien siempre con un carácter fragmentario, sin llegar a constituir un completo estatuto familiar para la pareja. Más aún, pareciera que sus soluciones están supeditadas al término de la relación, dado que durante la vida en común, el concubinato se caracteriza por su naturaleza de unión libre, que no crea ningún régimen especial para las adquisiciones que pudiesen hacer los concubinos y que no impone ninguna obligación de contribuir a los gastos del hogar común o a las deudas contraídas por uno de los miembros de la pareja.

tiene por causa la mantención, reanudación o la remuneración de las relaciones entre los concubinos, que será nula por causa ilícita, y los casos donde la donación tiene por fin reconocer los cuidados y servicios prestados por uno de los concubinos, reparar los perjuicios materiales o morales sufridos por uno de ellos, o incluso asegurar una subsistencia digna a uno de los concubinos, después de la muerte del donante, la cual será lícita. v. CHAINE NOTARIALE DE RECHERCHES ET D'APPLICATIONS EN DROIT DES AFFAIRE: Les contrats entre époux, parents et concubins. Aspects juridiqueset fiscaux. París: Litec. 1984. Pág. 28.

18. Ibídem. Págs. 35-36.

19. MALAURIE y FULCHIRON, ob. cit. Pág. 157.

20. BÉNABENT, Albert: Droit civil de la famille. $11^{\circ}$ edición. París: Litec. 2003. Pág. 17.

Revista de Ciencias Sociales - Número 64 (2014) - Universidad de Valparáíso - ISSN 0716-7725-Valparaíso, Chile 
Por el contrario, después de la separación, y a pesar del carácter libre y desformalizado de la terminación del concubinato, como consecuencia de esta evolución en la legislación y la jurisprudencia, se pueden encontrar un cierto número de efectos de carácter patrimonial, destinados a restaurar la equidad entre los miembros de la unión y a proteger a aquel que se encuentra en una situación más vulnerable ${ }^{21}$. Así, una vez que se ha producido la ruptura y pese a la inexistencia de un verdadero régimen matrimonial, puede ser necesario liquidar los intereses comunes creados como consecuencia de la adquisición de bienes de manera conjunta por los miembros de la pareja, o de la creación de riquezas a causa del trabajo en común de los concubinos, en una operación que se encontrará sujeta a las reglas del Derecho común, a través de las figuras de la sociedad de hecho o del enriquecimiento sin causa; en tanto que otros derechos reconocidos a los concubinos buscan asegurar la vivienda familiar después de la muerte o el abandono de uno de los miembros de la pareja, permitiéndole continuar con el contrato de arrendamiento (Ley de 6 de julio de 1989, artículo 14); permitir una reparación del perjuicio material o moral sufrido por uno de los concubinos, a causa de la muerte de su compañero, según lo ha establecido la jurisprudencia de la Corte de Casación en materia de responsabilidad extracontractual, a partir de los artículos 1382 y 1383; y conferir ciertos beneficios en materia de seguridad social.

Sin embargo, esta mutación en las concepciones sociales referidas a la autonomía sexual y a la validación pública de las parejas de distinto sexo que han decidido desarrollar sus vidas en común fuera del matrimonio, no tuvo un impacto inmediato en la manera como las relaciones entre las parejas del mismo sexo eran consideradas por el Derecho $^{22}$. En efecto, este absoluto desconocimiento del concubinato

21. MALAURIE y FULCHIRON. Ob. cit. Págs. 167-175.

22. Como ha destacado Bach-Ignasse, esta primera protección conferida al concubinato notorio heterosexual, a partir de los años setenta, no alteró de forma alguna la manera como era tratada la convivencia entre personas del mismo sexo. Por el contrario, según señala el mismo autor, uno de los primeros reconocimientos públicos de estas parejas vino de un pastor, marginal en su Iglesia bautista, llamado Joseph Doucé, de quien vendría la iniciativa de celebrar 'bendiciones

Facultad de Derecho y Ciencias Sociales - Universidad de Valparaíso - Chile 
entre personas del mismo sexo quedaría prontamente en evidencia: después de una primera decisión de la Cámara social, que versó sobre la aplicación del artículo 13 de la Ley de 2 de enero de 1978 relativa a la generalización de la seguridad social ${ }^{23}$, la Tercera Cámara civil de la Corte de Casación debió resolver un importante asunto referido al reconocimiento de la calidad de concubino notorio de uno de los miembros de la pareja después de la muerte del otro, a efectos de lo dispuesto en el artículo 14 de la Ley de 6 de julio de 1989. En su decisión de 17 de diciembre de 1997, la Corte resolvió que la doctrina del concubinato no puede ser aplicada a las uniones homosexuales, toda vez que "el concubinato no puede sino resultar de una relación estable y continua que tenga la apariencia de un matrimonio, por tanto entre un hombre y una mujer"'24. De esta manera, según la decisión de la Corte, resultaba imposible recurrir a la protección que proporcionaba esta figura, por lo que no existiría ningún equivalente legal a la figura del concubinato que protegiese a las parejas del mismo sexo. Como es imaginable, esta decisión y sus consecuencias animaron a los sectores que demandaban un efectivo reconocimiento y protección para las

de amor y amistad' para los homosexuales y las lesbianas. Después de su llegada a París, el pastor Doucé celebrará más de 130 de estas ceremonias (dos tercios de ellas para mujeres) antes de su asesinato en 1990. BACH-IGNASSE, Gérard: "Familles et homosexualités". En: Borrillo, Daniel. Homosexualités et droit. De la tolérance sociale à la reconnaissance juridique. París: PUF. 1998. Pág. 125.

23. Según esta disposición, la persona que vive maritalmente con un asegurado social y que se encuentra a su cargo de una manera efectiva, total y permanente, tiene la calidad de beneficiario del asegurado en los casos de seguro por enfermedad y maternidad. En su decisión de 11 de julio de 1989, la Corte resolvió que "Pero atendido que, refiriéndose el artículo 13 de la Ley de 2 de enero de 1978 a la noción de vida marital, el legislador ha por la misma entendido limitar los efectos de Derecho, con respecto a los seguros de enfermedad y maternidad, a la situación de hecho consistente en la vida común de dos personas que han decidido vivir como cónyuges, sin por tanto unirse por matrimonio, lo que no puede sino concernir que a una pareja constituida por un hombre y una mujer". Decisión de la Cámara Social de la Corte de Casación (1989): № 86-10.665, de 11 de julio de 1989.

24. Decisión de la Tercera Cámara Civil de la Corte de Casación (1997): Nº 9520.779, de 17 de diciembre de 1997.

Revista de Ciencias Sociales - Número 64 (2014) - Universidad de Valparáíso - ISSN 0716-7725-Valparaíso, Chile 
parejas del mismo sexo por parte del Derecho de la familia y tendrá una significativa influencia sobre la futura aprobación del pacs $^{25}$.

\section{La reivindicación de un nuevo modelo accesible a todos: el PACS y sus principales características}

Después de varios intentos fallidos de regulación ${ }^{26}$, una nueva proposición de ley apoyada por todos los partidos de la izquierda fue

25. En este sentido, según ha dicho Courtray "El pacs encuentra sus orígenes en las reivindicaciones de reconocimiento jurídico de las parejas homosexuales, relegadas al espacio del no Derecho por la jurisprudencia de la Corte de casación. Frente a la hecatombe que provoca en Francia la epidemia del SIDA en el curso de los años 1982-1996, se desarrolló entre las personas homosexuales un fuerte sentimiento de injusticia dada la negación en la cual estaban relegadas sus parejas frente al riesgo de muerte". COURTRAY, François: "Pacte civil de solidarité: une occasion manqué". En: Revue de Droit sanitaire et social, 2000, N ${ }^{\circ}$ 1, enero-marzo, 2000. Págs. 1-32. Disponible en línea en: http:// www.dalloz.fr/documentation/Document? id=RDSS\%2fCHRON\% 2f2000\%2f0001\& ctxt=0_YSR0MT1jb3VydHJhecKneCRzZj1wYWdILXJIY2hlcmNoZQ\%3d\%3d\&ctxtl=0 cyRwYWdlTnVtPTHCp3MkdHJpZGF0ZT1GYWxzZcKncyRzbE5iUGFnPTIwwqdzJ GlzYWJvPVRydWXCp3Mkb25nbGV0PQ\%3d\%3d\#TargetSgmIIdRDSS/CHRON/ 2000/0001 [Fecha última consulta 28 de abril de 2014].

26. El primer proyecto de ley que concierne a las parejas del mismo sexo fue presentado el 25 de junio de 1990 por el senador Jean-Luc Melenchon, quien propuso la creación de un contrat de partenariat civil. Este contrato, si bien inspirado en la entonces novedosa regulación danesa de 1989, buscaba dar solución a las problemáticas propias al reconocimiento de la familia de las parejas del mismo sexo por vía de crear una nueva figura, que a diferencia de la unión civil danesa no estaría destinada exclusivamente a las personas que forman un proyecto de vida en común, ni va a exigir la existencia de elementos afectivos y sexuales en la relación a regular: por el contrario, el contrato se propone como una regulación neutra y universal, que no se encuentra solamente abierta a las parejas, sino también a todas las personas que quieran vivir juntas, incluso si aquellas son unidas por un vínculo de parentesco. En 1992, una segunda moción parlamentaria fue presentada a la Asamblea nacional por un grupo de diputados: el contrat d'union civile. De la misma manera que el contrat de partenariat civil, el contrat d'union civile estaba abierto a toda persona soltera, sujeto en todo caso a una importante excepción, desde el momento que el contrato no podría ser celebrado entre ascendientes y descendientes. Por esta razón, una parte de la doctrina consideró que la figura propuesta se encontraba abierta tanto a las parejas de distinto como del mismo sexo, como a toda otra forma de cohabitación amical o familiar, con

Facultad de Derecho y Ciencias Sociales - Universidad de Valparaíso - Chile 
presentada a la Asamblea nacional el día 1 de octubre de 1998: se trata del pacte civil de solidarité. Este nuevo proyecto crea una figura de origen contractual ${ }^{27}$ que, reconociendo la existencia de una verdadera vida en pareja $^{28}$, permite a quienes lo celebran — los pacsés—, organizar su vida en común, por vía de establecer una obligación de ayuda financiera mutua y un régimen de solidaridad para las deudas que cada parte

la excepción ya señalada. Después de una importante presión social, una tercera moción parlamentaria fue promovida el 23 de enero de 1997: el contrat d'union social, proyecto que será renovado por un grupo de senadores socialistas el 19 de marzo de 1997. Este contrato será apoyado por todos los partidos de izquierda durante la campaña electoral de 1997. En esta misma época, sería promovido un nuevo proyecto de regulación, el contrat d'union civile et sociale. En reacción a estas propuestas de ley sometidas a discusión en la Asamblea nacional, el Ministerio de Justicia, preocupado por el impacto de la nueva regulación sobre el número de matrimonios y nacimientos, encomendó al profesor Jean Hauser la redacción de un estudio que contengan alternativas a las diversas propuestas de ley. En este informe, conocido como el Informe Hauser, el citado profesor propuso la creación de un pacte d'intérêt commun, el cual se encontrará basado en una perspectiva diferente: como ha destacado el profesor Pillebout, en su intento por eliminar la carga ideológica del problema, propuso un marco jurídico destinado a regular únicamente las relaciones patrimoniales de los concubinos, a través de reglas que debían estar dispuestas en el Código civil, después del título que trata de las convenciones de indivisión. PILLEBOUT, Jean François: Le PACS. Pacte civil de solidarité. París: Litec. 2002. Pág. 2.

27. Como destacan Terré y Fenouillet, durante la discusión parlamentaria frecuentemente se destacó el hecho que la nueva institución que estaba siendo creada no se trataba sino de un estatuto de tipo patrimonial, destinado a regular cuestiones materiales. Sin embargo, esta lógica patrimonial es cuestionada por las restantes disposiciones del proyecto. En efecto, bajo esta lógica ¿Cómo explicar que el pacs no esté abierto a su celebración entre hermanos? ¿Cómo justificar que dos amigos que viven juntos no puedan celebrar esta convención? o finalmente ¿Por qué reducir sus contratantes a dos personas? TERRÉ, François y FENOUILLET, Dominique: Droit civil. La famille. $8^{\circ}$ edición. París: Dalloz. 2011. Pág. 293.

28. Este punto será reforzado por la decisión del Consejo Constitucional, según la cual "Considerando que resulta de estas disposiciones, iluminadas por los debates parlamentarios al fin de los cuales han sido adoptadas, que la noción de vida común no cubre solamente una comunidad de intereses que no se limita a la exigencia de una simple cohabitación entre dos personas; que la vida común mencionada por la ley en cuestión supone, además de una residencia común, una vida en pareja, que justifica que el legislador 
asume a fin de solventar los gastos de la vida en común (art. 515-4 CC), así como de regular cuál será el régimen aplicable a los bienes adquiridos durante la vida en común (art. 515-5 y ss. del CC) ${ }^{29}$.

Sin embargo, pese al carácter eminentemente patrimonial de los efectos que desarrollaba la figura que pretendía crearse, su tramitación no estuvo exenta de dificultades. De partida, debió afrontar un rechazo inicial por parte de diputados de derecha, que votaron su inadmisibilidad por inconstitucionalidad, lo que obligó a reintroducir la moción en noviembre de 1998, con pequeñas modificaciones. Como resulta esperable después de este primer incidente ${ }^{30}$, el proyecto sería objeto de un arduo debate parlamentario, que incluyó un discurso de cinco horas por parte de la diputada Christine Boutin, defendiendo los fundamentos de la sociedad francesa, posibles de encontrar en la Biblia ${ }^{31}$. En total, más de 70 horas de debate serían dedicadas a su discusión entre el 3 de noviembre y el 3 de diciembre, breve período de tiempo durante el cual más de 300 indicaciones al proyecto serían realizadas por sus detractores $^{32}$. Pese a la oposición de una parte importante de los diputados, la proposición será finalmente aprobada, debiendo pasar al Senado para su revisión.

haya previsto causales de nulidad el pacto, sea porque retoman los impedimentos para contraer matrimonio destinados a prevenir el incesto, sea porque evitan una violación de la obligación de fidelidad derivada del matrimonio; que en consecuencia, sin definir expresamente el contenido de la noción de vida en común, el legislador ha determinado los componentes esenciales". Decisión del Consejo Constitucional (1999): N 99-419, de 9 de noviembre de 1999.

29. Como se verá, el régimen de bienes aplicables al pacto civil fue objeto de una modificación durante el año 2006.

30. El cual con posterioridad daría lugar a uno de los fundamentos formales de inconstitucionalidad del proyecto, el cual sería rechazado por el Consejo Constitucional.

31. GODARD, Joëlle: "PaCS Seven Years On: Is It Moving Towards Marriage?" En: International Journal of Law, Policy and the Family, 2007, Nº 21, pág. 132.

32. Todas estas circunstancias llevaron a Vivier a afirmar que "La batalla parlamentaria estuvo marcada por una obstrucción sistemática de la oposición, al menos en la Asamblea”. VIVIER, Jean-Loup. Ob. cit. Pág. 13.

Facultad de Derecho y Ciencias Sociales - Universidad de Valparaíso - Chile 
En medio de fuertes presiones sociales "por" y "contra" la nueva institución, el Senado rechazó en su primera lectura la moción, reemplazando la figura contractual propuesta por la Asamblea por una ampliación por vía legal de la definición de concubinato, incorporando un nuevo artículo en el Código que remediase la situación creada por la decisión de la Corte, sin importar la creación de una nueva institución: según esta disposición "El concubinato es una unión de hecho, caracterizado por una vida en común que presenta un carácter de estabilidad $y$ de continuidad, entre dos personas, de sexo diferente o del mismo sexo, que viven en pareja"33. En su segunda lectura, en contra de la opinión del Senado, la Asamblea insistió en la idea de crear esta nueva figura, aunque por razones políticas efectuó ciertas modificaciones destinadas a destrabar la discusión, como fue el excluir la posibilidad de celebración de un pacs entre parientes ${ }^{34} \mathrm{y}$ el limitar al matrimonio las reglas que conciernen a la reproducción, rechazando el acceso por parte de los pacsés a la adopción y a la procreación médica asistida. Sin embargo, a pesar de las modificaciones, el Senado rechazó discutir la proposición en una segunda lectura, situación que obligó a formar una comisión paritaria mixta durante el mes de mayo de 1999, la cual terminará también sin un acuerdo. Finalmente, la moción será aprobada por la Asamblea en su tercera lectura, recurriendo al mecanismo previsto en el artículo 45 inciso final de la Constitución para desbloquear las controversias entre las cámaras. De esta forma, después de muchos años de reivindicaciones asociativas y de proyectos de ley abortados, el 13 de

33. Si bien en definitiva sería el criterio de la Asamblea el que terminaría por imponerse, esta definición será de todas formas incluida en el artículo 515-8 del Código civil.

34. Esta decisión legislativa quedaría reflejada en el artículo 515-2 del Código civil, disposición conforme a la cual "Bajo pena de nulidad, no podrá haber pacto civil de solidaridad:

$1^{\circ}$ Entre ascendiente y descendiente en línea directa, entre parientes en línea directa y entre colaterales hasta el tercer grado incluido;

$2^{\circ}$ Entre dos personas de las que al menos una esté comprometida por los vínculos del matrimonio;

$3^{\circ}$ Entre dos personas de las que al menos una esté ya vinculada por un pacto civil de solidaridad". 
octubre la Asamblea nacional adoptará por 315 votos contra 249 una ley que introduce una nueva figura en el Código civil, por vía de incluir un nuevo Título XIII al Libro I del Código, titulado "Du pacte civil de solidarité et du concubinage"

Como podía anticiparse a causa de la fuerte resistencia que generó durante el debate parlamentario, el proyecto fue sometido antes de su promulgación al control del Consejo Constitucional por un requerimiento de 60 senadores y 60 diputados, fundado en el artículo 61 inciso $2^{\circ}$ de la Constitución. En su decisión 99-41935, el Consejo rechazará la declaración de inconstitucionalidad solicitada, entre otros motivos, por la indeterminación del contenido de la "vida en común" y de la "ayuda mutua y material" que estructuran la base de la nueva regulación ${ }^{36}$, fijando la interpretación ${ }^{37}$ del nuevo artículo 515-1 del Código civil ${ }^{38}$, de una manera que, como ha señalado Caballero, va a terminar por conferir al pacs una orientación decididamente sexual, desde el momento que afirma que la vida en común no cubre solamente una comunidad de intereses y no se limita a una cohabitación entre dos personas, con lo cual quedará enmarcada decididamente dentro del Derecho de las sexualidades y no solamente en el Derecho de los contratos $^{39}$. Finalmente, la Ley $\mathrm{N}^{\circ}$ 99-944 será promulgada el día 15 de noviembre de 1999.

35. Decisión del Consejo Constitucional (1999): $\mathrm{N}^{\circ}$ 99-419, de 9 de noviembre de 1999.

36. Cuestión que a juicio de los requirentes implicaría una violación de la reserva legal, en la medida que obligaría a la autoridad reglamentaria y judicial a intervenir a fin de llenar las lagunas e imprecisiones de la ley.

37. Explicando esta figura, señala el profesor Cabrillac que desde hace una decena de años, el Consejo ha desarrollado una solución intermedia entre la declaración de inconstitucionalidad y el rechazo del requerimiento, la conformidad con reservas. De esta forma, el Consejo declara constitucionales ciertas figuras objeto de requerimiento, bajo reserva que la interpretación que sea hecha corresponda a aquella que el Consejo ha dado en su decisión, permitiéndose el Consejo interpretar la ley e incluso, en ciertas ocasiones, llegar a incorporar nuevos elementos a las disposiciones. CABRILLAC, Rémy. Ob. cit. Pág. 109.

38. V. nota 21.

39. CABAllero. Ob. Cit. Pág. 285. En el mismo sentido, destaca Grimaldi, que el Consejo Constitucional, rechazando la interpretación sostenida por el

Facultad de Derecho y Ciencias Sociales - Universidad de Valparaíso - Chile 
El pacto civil de solidaridad, que se define en el artículo 515-1 del Código como "un contrato celebrado entre dos personas físicas mayores de edad, de sexo diferente o del mismo sexo, para organizar su vida común”"40, es una nueva institución en el Derecho de la familia francés, que proporciona a los miembros de la pareja una regulación relativamente completa de los aspectos patrimoniales de su vida en común. En efecto, desde la celebración del contrato, los pacsés asumen la obligación recíproca de proporcionarse la ayuda material que requieran, de manera proporcional a sus respectivas facultades económicas (art. 515-4 inciso $1^{\circ} \mathrm{CC}$ ), al tiempo que son considerados solidariamente responsables frente a terceros para el pago de las deudas contraídas por uno de ellos a fin de solventar las necesidades de la vida corriente y de la vivienda común (art. 515-4 inciso $2^{\circ} \mathrm{CC}$ ). Finalmente, la celebración del pacs sujeta las adquisiciones que hagan las partes durante la vigencia del pacto a un régimen de bienes, sea el régimen de indivisión si así lo han pactado, sea la separación de patrimonios en ausencia de una convención (art. 515-5 y ss CC).

gobierno en orden a que el pacs no implicaba necesariamente la existencia de relaciones sexuales entre las partes, declarará que es un contrato destinado a dos personas que viven en una unión sexual, cuestión que quedaría bien reflejada en las prohibiciones de celebración y en el hecho que sólo pueda ser celebrado por dos personas. GRIMALDI, Michel: "El pacto civil de solidaridad en el Derecho francés". En: Revista Chilena de Derecho Privado, Fundación Fernando Fueyo, 2004, N 3. Págs. 72-73.

40. Otra definición, más completa y que resalta las características del pacto, es proporcionada en el Vocabulario Jurídico publicado bajo la dirección del profesor Gérard Cornu, que lo define como una "Modalidad convencional de organización de la vida común entre dos personas físicas mayores de edad, indistintamente abierto a las parejas heterosexuales u homosexuales (salvo impedimento de parentesco, de alianza, o de compromiso anterior), especie nueva de contrato civil típico (C.civ., art. 5151 y ss) que crea entre los miembros de la pareja una solidaridad por las deudas del hogar) y somete todos los bienes adquiridos a título oneroso posteriormente a la conclusión del pacs a una indivisión por mitades (la cual sin embargo puede ser excluida, según la naturaleza de los bienes, sea en la convención inicial, sea en el acto de adquisición), pacto que presente un carácter precario (puede ser disuelto de común acuerdo o por ruptura unilateral, en este sentido unión libre) y formalista (extrañas al estado civil, las formalidades de su formación, de su modificación o de su disolución son centralizadas en el secretario judicial del tribunal de instancia”. CORNU, Gérard: Vocabulaire juridique. $8^{\circ}$ edición. París: PUF. 2007. Pág. 651.

Revista de Ciencias Sociales - Número 64 (2014) - Universidad de Valparáíso - ISSN 0716-7725-Valparáiso, Chile 
Por el contrario, los efectos personales del pacs son más bien limitados, aunque se han ido ampliando progresivamente, lo que queda particularmente reflejado en lo que concierne al estado civil de los pacsés: mientras que, según la regulación de 1999, se trataba de un elemento que resultaba absolutamente extraño a esta regulación, cuestión que incluso fue constatada en la decisión 99-419 del Consejo Constitucional $^{41}$, después de la reforma de 2006 la mayoría de la doctrina se ha inclinado por la solución contraria, considerando que la inscripción del pacs en el margen del registro de nacimiento de cada uno de los miembros de la pareja, al igual como ocurre en el caso del matrimonio, simbólicamente lo establece como una verdadera forma de unión, que impide que el pacsé pueda ser en lo sucesivo visto como soltero ${ }^{42}$. Sin embargo, hasta la fecha su celebración no crea un vínculo de alianza entre los parientes consanguíneos de uno de los miembros de la pareja con el otro, ni impone propiamente un régimen primario de deberes, lo que lo diferencia de lo que ocurre con el matrimonio ${ }^{43}$. Finalmente, la unión tendrá siempre un carácter precario, desde el momento que una de las causas de disolución es la voluntad unilateral de uno de los miembros de la pareja (art. 515-7 inciso $\left.3^{\circ} \mathrm{CC}\right)^{44}$.

41. BÉNABENT, Albert. Ob. cit. Pág. 300; GRIMALDI, Michel: "El pacto civil de solidaridad en el Derecho francés". En: Revista Chilena de Derecho Privado, Fundación Fernando Fueyo, 2004, N³ págs. 74-75.

42. GODARD. Ob. cit. Pág. 317. En el mismo sentido, destacan Terré y Fenouillet que "Este nuevo modo de publicidad del pacs marca un avance en la aproximación del matrimonio y del pacs, por la integración de éste en el derecho de las personas y del estado civil. Desde que la calidad de partenaire es, como la de cónyuge, un elemento del estado civil en el sentido del artículo 34 Código civil, es necesario que ella figure sobre las actas de estado civil, con la mención de la identidad del otro partenaire". TERRÉ y FENOUILLET, ob. cit. Págs. 300-301.

43. Como destaca el profesor Grimaldi, el pacs no genera ninguna obligación personal entre las partes, no existe un deber de fidelidad, ni de socorro, ni un deber propiamente de formar una comunidad de vida, tratándose éste más bien de un elemento que debe existir al momento de celebrarse el acuerdo, so pena de nulidad. GRIMALDI, ob. cit. Pág. 74.

44. La posibilidad de poner término unilateral al pacs fue objeto de control por parte del Consejo Constitucional, ante el requerimiento formulado por un grupo de diputados fundado en su posible contravención a los principios

Facultad de Derecho y Ciencias Sociales - Universidad de Valparaíso - Chile 
Como se puede apreciar, el pacs presenta importantes diferencias con el otro estatuto formal de regulación de la vida en común —el matrimonio-, las cuales han sido bien resumidas por la profesora Godard, al decir que:

Mientras los matrimonios son anunciados y celebrados en la Municipalidad, en presencia de al menos dos testigos, seguido de una ceremonia religiosa si los cónyuges lo desean, el pacs es simplemente registrado por el Secretario Judicial del Tribunal de Instancia. Un pacs registrado puede ser disuelto sin intervención judicial a través de un procedimiento administrativo que se basa en el mutuo consentimiento de los pacsés o incluso por una declaración unilateral de uno de ellos. El pacs no crea una obligación de fidelidad entre los pacsés y ninguna obligación de mantenimiento persiste después de la disolución. Más aún, en caso de conflicto entre los compañeros después de la disolución, el caso será resuelto por el juez del Tribunal de Gran Instancia, quien normalmente conoce de contratos, y no por el juez de asuntos familiares, quien conoce de asuntos familiares, como el divorcio. Esto fue confirmado por la Corte de Apelaciones de Douai, porque el artículo 587-7 del Código civil no especifica qué juez es competente ${ }^{45}$.

De la misma forma, y a pesar de su precariedad, el pacs presenta también importantes diferencias con el concubinato, que comienzan por el carácter de simple unión de hecho que tiene este último (art. 515-8 CC) frente a la naturaleza contractual, y por tanto formal del primero, y que se expresan de una manera clara si uno considera que el pacs crea una verdadera situación legal, a la cual son vinculadas una serie de consecuencias jurídicas propias, que permiten identificar un

fundamentales del Derecho de los contratos. En su decisión $N^{\circ}$ 99-419, el Consejo consideró conforme a la constitución la nueva regulación, en el entendido que en todos los casos de ruptura unilateral (incluso, en el matrimonio) el otro miembro de la pareja está legitimado para demandar una reparación. Decisión del Consejo Constitucional (1999): No 99-419, de 9 de noviembre de 1999, considerando 62.

45. GODARD, Joëlle. Ob. cit. Pág. 313.

Revista de Ciencias Sociales - Número 64 (2014) - Universidad de Valparáíso - ISSN 0716-7725-Valparáiso, Chile 
nuevo estatuto legal, al contrario del carácter fragmentario que todavía conservan las soluciones legales y jurisprudenciales asociadas al concubinato.

Considerando las diferencias expuestas, se puede identificar en el pacs una nueva forma de regular la vida en pareja, diferente del matrimonio y del concubinato, y por esta razón, dotada de su propia identidad en el Derecho de la familia, que goza de una legitimidad independiente de las otras expresiones que puede adoptar la realidad familiar, cuestión que se expresa, por ejemplo, en el creciente número de contratos celebrados desde su debut el año 1999: de 22.271 celebrados el año 2000, a 205.558 el año $2010^{46}$. En este proceso de consolidación del pacs ha tenido una importancia fundamental las reformas introducidas en $2005^{47}$ y $2006^{48}$ (ambas respaldadas por parlamentarios de derecha, lo que en sí da cuenta de un importante cambio), lo cual puede apreciarse en el hecho que, una vez introducidas estas

46. INSTITUT NATIONALE DE LA STATISTIQUE ET DES ÉTUDES ECONOMIQUES (INSEE), Statistiques sur l'évolution du nombre de mariages et de pacs conclus jusqu'en 2012. Disponible en línea en: http://www.insee.fr/fr/themes/ tableau.asp? ref_id=NATTEF02327 [Fecha última consulta 28 de abril de 2014]

47. Como ha destacado la profesora Godard, la Ley de 2005 suprimió la exigencia de duración mínima de tres años a fin de permitir que los miembros de la pareja que celebraron un pacs puedan someterse a un régimen tributario conjunto, que resulta más beneficioso, situación que permite explicar el aumento del número de celebraciones experimentada en 2005 (60.233), en comparación a los 39.864 celebrados en 2004. GODARD, Joëlle. Ob. cit. Págs. 315-316.

48. En 2006, una nueva ley ( $\mathrm{N}^{\circ} 2006-728$, de 23 de junio de 2006) tuvo por principal objeto reformar las tasas de los impuestos aplicables a las liberalidades entre los pacsés. Sin embargo, ella introdujo otras importantes modificaciones a la regulación de 1999, que han favorecido la celebración del contrato: desde la reforma, el secretario judicial del Tribunal de Instancia debe comunicar al oficial de estado civil la celebración del PaCS, a fin que este último la pueda anotar al margen del acta de nacimiento de cada uno de los miembros de la pareja, indicando además el nombre de su compañero; el régimen de separación de patrimonios reemplazó a la indivisión como régimen supletorio, en ausencia de acuerdo; y para el compañero supérstite, si bien la ley no le reconoce calidad de heredero, se le confiere el derecho a gozar a título gratuito de la vivienda que sirvió de residencia a la pareja, durante el término de un año contado desde la fecha de la muerte. v. GODARD, Joëlle, ob. cit. Págs. 317-319.

Facultad de Derecho y Ciencias Sociales - Universidad de Valparaíso - Chile 
modificaciones, se produjo un aumento explosivo en el número de pacs celebrados: si el año 2006, 77.347 contratos fueron celebrados, el año 2007 esta cifra va a aumentar a 101.999, para terminar el año 2010 con 205.558 pacs celebrados ${ }^{49}$. Sin embargo, esta nueva institución no se ha encontrado exenta de críticas, por parte de la doctrina conservadora e incluso de ciertos sectores progresistas.

Más allá de la crítica a los aspectos técnicos de la ley, para sectores conservadores el pacs y su apertura al mundo homosexual resulta absolutamente disonante con las finalidades propias del Derecho de la familia, dado que viene a afectar tanto la posición de preeminencia que la legislación debe conceder al matrimonio como modelo de organización de la vida familiar, como la relación entre regulación de la vida en pareja con el nacimiento y crianza de los hijos. Estas críticas han sido bien resumidas por Caballero, cuando destaca que:

"Detrás del decano Carbonnier para quien el pacs constituye un riesgo de debilitamiento del matrimonio, los especialistas del derecho de la familia denuncian los peligros, lagunas e imperfecciones del proyecto. Para M. Malaurie, la idea misma de pareja homosexual resultaba inadmisible, pues 'la homosexualidad es la negación del orden familiar', sin considerar sus efectos 'sobre el nacimiento y la educación de los hijos'. Para M. Terré, se trata de una ley 'mal pensada', 'descarriada' por consideraciones demagógicas, 'fruto de agitaciones parisinas marginales' que marca 'una nueva etapa en el sentido de una descomposición de la familia'. Para M. Cabrillac, el texto es 'hipócrita', 'peligroso en sus aplicaciones' y contrario a la concepción de pareja 'defendida por la inmensa mayoría de las corrientes espirituales de nuestro país'" ${ }^{50}$.

Por el contrario, las críticas del sector progresista se centraron en el carácter limitado de los efectos del pacs en comparación con los del matrimonio, cuestión que impediría un pleno reconocimiento de la

49. INSEE, ob. cit.

50. CABAllero, François, ob. cit. Págs. 283-284. 
pareja homosexual, creando una verdadera "jerarquía de las sexualidades", donde el pacs ocupa un lugar inferior, haciendo las veces de una suerte de "semi-matrimonio". Esta visión crítica ha sido bien expresada por el profesor Borrillo, quien destaca que bajo la lógica de la nueva regulación las uniones homosexuales son aceptadas bajo la condición que ellas no vengan a poner en peligro la dimensión "modélica" reservada al matrimonio, en cuanto lugar simbólico donde la diferencia de sexos, en tanto valor político y cultural, se lleva a cabo. De esta forma, continúa el autor en su crítica, la segregación de las parejas aparece así como una necesidad antropológica, destinada a preservar esta diferencia: así como la vieja doctrina del "separate but equal" servía para justificar el régimen del apartheid con respecto a los negros, la homofobia diferencialista pretende alejar a los homosexuales del Derecho común y en particular del matrimonio, a fin de salvaguardar la supremacía normativa de la heterosexualidad ${ }^{51}$.

Como puede apreciarse de la crítica del profesor Borrillo (expresión a su vez del sentir de una parte importante de las organizaciones LGBT) el pacs, si bien suponía una primera solución inclusiva para las parejas del mismo sexo, con un marcado carácter igualitario, en la medida que estaba destinado indistintamente a las parejas del mismo o de distinto sexo, presentaba el inconveniente de lograr este objetivo por vía de la creación de un nuevo estatuto, lo que implicaba simbólicamente el establecimiento de una diferenciación entre los distintos tipos de parejas (quienes podían acceder al matrimonio y quienes no), al tiempo que conservaba para este último una posición de preeminencia en la regulación de las relaciones de pareja. Por esta razón, no es de extrañar que, a pesar del creciente éxito que presentaba el pacs y de su cada vez mayor utilización por las parejas,

51. BORRILLO, Daniel. Ob. cit. Págs. 76-77. El mismo autor ha destacado que "Lejos de proscribir la discriminación o de proporcionar un marco legal equivalente, el pacs ha relegado tanto práctica como simbólicamente a las parejas del mismo sexo a un status inferior, en comparación a las parejas de distinto sexo. La jerarquía conyugal, al tope de la cual encontramos al matrimonio, revela la existencia de una lógica que sirve como justificación política". BORRILLO, Daniel: "Who Is Breaking With Tradition? The Legal Recognition of Same-Sex Partnership in France and the Question of Modernity". En: Yale Journal of Law and Feminism, 89, 2005, pág. 92.

Facultad de Derecho y Ciencias Sociales - Universidad de Valparaíso - Chile 
se formulasen crecientes demandas a fin de abrir el matrimonio a las parejas del mismo sexo. En la sección siguiente se analizará de manera sumaria los antecedentes de la reciente ley que abre el matrimonio a las parejas de personas del mismo sexo (Ley N ${ }^{\circ} 2013-404$, de 17 de mayo de 2013) $)^{52}$.

\section{La evolución del debate: desde la aprobación del PACS a la discusión sobre el matrimonio homosexual}

Desde que la noción de matrimonio-contrato apareció en el marco de las reflexiones sobre esta institución, ha servido para justificar la competencia de los poderes temporales para legislar sobre la materia. Mas esta teoría, desarrollada en etapas sucesivas por la escolástica tardía, por los reformadores y los humanistas del siglo XVI, y especialmente por la Escuela del Derecho Natural, conocerá su apogeo durante la Ilustración: para los filósofos de esta época, el matrimonio es solamente una institución de Derecho natural y común a todos los hombres, que tiene una naturaleza de contrato civil y que, de la misma forma que todos los contratos, se encuentra determinado por la voluntad de las partes y por su propia naturaleza, sin tener un vínculo especial con la divinidad ${ }^{53}$. Es en este contexto que Voltaire afirmará la primacía del

52. En este punto, cabe destacar también que el matrimonio cuya apertura se demanda no corresponde al modelo no igualitario, opresivo y "burgués" propio

del "contrato de género" que fue descrito al inicio de este trabajo, sino a otro construido desde la dimensión asociativa, reflejo de la renovación continua de la voluntad de estar juntos que comparten los cónyuges y que pone el acento en las responsabilidades que éstos comparten, desde una posición de igualdad, que es fruto de los cambios sociales y legislativos habidos durante el siglo XX. Más aún, la apertura del matrimonio a las parejas del mismo sexo supone profundizar la comprensión del matrimonio desde esta dimensión asociativa, como una forma especial de compromiso por medio de la cual dos personas deciden compartir sus vidas, formando un proyecto familiar en común reconocido y protegido por el ordenamiento, como se ha destacado por Paternotte a propósito de la resignificación de la institución que implica el matrimonio igualitario. Sobre este último punto, v. PATERNOTTE, David: "Matrimonio 'homosexual' y ciudadanía: hipótesis de la resignificación”. En: Nomadías, 2009, $\mathrm{N}^{\circ}$ 10: pássim.

53. COING, Helmut: Derecho privado europeo. Derecho común más antiguo. (1500 1800). Tomo I. Madrid: Fundación Cultural del Notariado. 1996. Pág. 290.

Revista de Ciencias Sociales - Número 64 (2014) - Universidad de Valparáíso - ISSN 0716-7725-Valparáiso, Chile 
aspecto contractual y por ende del carácter "civil" del matrimonio, sin aventurarse a negar su aspecto sacramental: "El matrimonio es un contrato del Derecho de gentes, del cual los católicos romanos han hecho un sacramento. Mas el sacramento y el contrato son dos cosas bien diferentes: a uno son atribuidos los efectos civiles, al otro las gracias de la Iglesia" ${ }^{\prime \prime}$.

Esta corriente filosófica tendrá una gran influencia acentuando las tendencias secularizadoras y racionalistas que justifican el incremento de las competencias afirmadas por los diversos Estados para intervenir en los cada vez más amplios ámbitos considerados como puramente seculares ${ }^{55}$. Bajo esta influencia, el matrimonio tendrá su primera regulación puramente secular en Francia ${ }^{56}$, y ésta no estará contenida en una ley, sino en la Constitución misma: según el Título II del artículo 7 de la Constitución de 1791 "La ley no considera el matrimonio que como un contrato civil...". Esta declaración de principios será concretada ulteriormente por el decreto legislativo de 20 de septiembre de 1792, y a la postre incorporada en los artículos 63 y siguientes (Des Actes de Mariage) y 144 y siguientes (Du Mariage) del Código civil; y, a diferencia de la otra gran trasformación que el matrimonio experimentó durante la época revolucionaria (el divorcio), la laicización no será revertida por el régimen de la restauración: la Ley Bonald de 8 de mayo de 1816 concernirá solamente al divorcio y no al matrimonio civil, posiblemente porque en esta última se puede reconocer una afirmación de poder civil (republicano o monárquico, mas civil) frente al poder de la Iglesia católica y de Roma.

Esta antigua tradición, que afirma el matrimonio como institución civil y su naturaleza contractual, será retomada en nuestros

54. VOLTAIRE, citado en GAUDEMET, Jean: "Sociétés et mariage". En: Gaudemet, Jean. Sociétés et mariage. Estrasburgo: Cerdic-Publications. 1980. Págs. 441-442.

55. BASDEVANT-GAUDEMET, Brigitte y GAUDEMET, Jean: Introduction historique au Droit XIII ${ }^{e}-X X^{e}$ Siècles. París: L.G.D.J. 2000: Pág. 323.

56. Si bien debe destacarse que, al término del Antiguo Régimen, el Edicto de Tolerancia de 1787 había introducido la posibilidad para los protestantes y los judíos de hacer registrar su matrimonio y el nacimiento de sus hijos por un juez, a fin de permitirles obtener un estado civil.

Facultad de Derecho y Ciencias Sociales - Universidad de Valparaíso - Chile 
días por los partidarios del matrimonio homosexual, a fin de justificar la apertura de esta institución a las parejas del mismo sexo. En ese preciso sentido, cabe destacar la argumentación desarrollada por el profesor Borrillo, en orden a que:

"La Revolución Francesa de 1789, como también el Código civil napoleónico de 1804, reimaginaron la institución del matrimonio como un contrato fundado en la voluntad abstracta de las respectivas partes, antes que como una unión de las carnes establecida por un sacramento religioso. En esta concepción secular del matrimonio, la cual es constitucional en su naturaleza, la ceremonia religiosa es privada de toda consecuencia legal, y los ciudadanos, para estar legalmente casados, deben validar su unión frente a un representante del Estado. Los actuales reclamos políticos de los movimientos gay y lésbicos enfatizan estos mismos elementos, aunque en una forma ligeramente más radical" 57 .

En adición a esta primera argumentación, fundada en la tradición republicana y secular de la regulación del matrimonio en el Derecho francés, los partidarios del matrimonio homosexual destacaron el hecho que ninguna disposición del Código establece como una exigencia para la celebración del matrimonio la diferencia de sexos de los esposos, remarcando que no existía prohibición alguna en la legislación, a diferencia de lo que ocurría con la bigamia (art. 147 CC) y con el incesto (art. 161, 162 y 163 CC). Sin embargo, estos razonamientos no recibieron respaldo por parte de la mayoría de la doctrina civilista francesa, que consideró a partir del antiguo artículo 140 del Código civil ${ }^{58}$ que la diferencia de sexos entre los esposos era una condición de validez del matrimonio ${ }^{59}$. En este sentido, como han destacado los profesores Terré

57. BORRILLO, Daniel (2009), ob. Cit. 89.

58. Según la redacción que presentaba antes de la reforma de 2013, "El hombrey la mujer no pueden contraer matrimonio antes de cumplir 18 años".

59. Como ha señalado el profesor Bénabent "No es sino implícitamente que el artículo 144 del Código civil hace alusión a la diferencia de sexos, en tanto esta condición parece evidente". BÉNABENT, Albert. Ob. cit. Pág 28. v. también, HAUSER, Jean y RENCHON, Jean-Louis (directores) (2012): Le statut juridique de la couple marié et de la couple non marié en Droit belge et français. Bruselas: Larcier. Pág. 416.

Revista de Ciencias Sociales - Número 64 (2014) - Universidad de Valparáíso - ISSN 0716-7725-Valparaíso, Chile 
y Fenouillet, un simple análisis de las disposiciones que forman parte del estatuto propio del matrimonio demuestra que en todo momento el legislador ha concebido la diferencia de sexos de los esposos como una condición para su celebración ${ }^{60}$. Esta interpretación sostenida por la mayoría de la doctrina recibió una última confirmación por parte de la Corte de Casación, que en su arrêt de principe de 13 de marzo de $2007^{61}$ decidió que según la ley francesa "El matrimonio es una unión de un hombre y de una mujer" agregando que "este principio no contradice ninguna de las disposiciones del Convenio europeo de derechos humanos ni de la Carta de derechos fundamentales de la Unión europea, que no tiene en Francia fuerza obligatoria" ${ }^{\prime 2}$.

60. Como destacan los autores citados "A esto, se ha natural y tradicionalmente respondido que, si los redactores del Código civil no han hecho esta condición, es porque ella venía de suyo. Por un lado, si ningún texto del Código hacía de la diferencia de sexos una condición del matrimonio, numerosas eran aquellas que en 1804, llevaban la huella de esta concepción. Es así que los artículos 212 a 226 del Código de Napoleón empleaban a la época veinte veces la palabra 'marido' y dieciséis veces la palabra 'mujer'. Y si la distinción de sexos no aparece actualmente sino solamente de manera excepcional en el Código, es porque los términos 'marido' y 'mujer' han sido sistemáticamente eliminados, sobre todo por la ley de 23 de diciembre de 1985 y por aquella de 26 de mayo de 2004, a fin de manifestar que los dos cónyuges tienen en adelante los mismos derechos. En lo que permanece, el artículo 75 del Código civil se mantiene claro cuando, describiendo la ceremonia de matrimonio por el oficial de estado civil, dispone: 'Recibirá de cada parte, una después de otra, la declaración de que desean tomarse por marido y mujer'. En cuanto a los artículos 162 y 163, prohibiendo únicamente el matrimonio entre 'el hermano y la hermana', 'el tío y la sobrina, la tía y el sobrino', marcan implícita, más necesariamente que la diferencia de los sexos es una condición del matrimonio iEn caso contrario, el matrimonio, prohibido entre hermano y hermana estaría permitido entre hermano y hermano o hermana y hermana!” TERRE y FENOUILLET, ob. cit. Pág. 74.

61. Decisión de la Primera Cámara Civil de la Corte de Casación (2007): $\mathrm{N}^{\circ}$ 05-16.627, de 13 de marzo de 2007. v. también, CABALLERO, François, ob. cit. Pág. 304; TERRÉ y FENOUILLET, Ob. cit. Pág. 75. Como ha destacado el profesor Borrillo, los orígenes de este proceso se encuentran en la decisión de Noël Mamère, alcalde por el partido verde del municipio de Bègles, de celebrar un matrimonio entre dos hombres (Bertrand Charpertier y Stéphane Chapin), ceremonia que contó con el apoyo de grupos de activistas y que se fundó en la ausencia de una definición de matrimonio como la unión entre un hombre y una mujer. BORRILLO, Daniel (2005), ob. cit. Págs. 93-94.

62. Esta interpretación del Convenio será confirmado de una manera indirecta por la propia Corte europea de Derechos Humanos en la sentencia Schalky Köpf c. Austria de 2010, donde la Corte decidió que, a pesar del hecho que las parejas

Facultad de Derecho y Ciencias Sociales - Universidad de Valparaíso - Chile 
Después de esta decisión, el Derecho francés experimentará una importante reforma el año 2008: a través de una modificación de la Constitución, se reconocerá la posibilidad directa de cuestionamiento de la constitucionalidad de una disposición legal, ante el Consejo Constitucional, por vía de la nueva question préjudicielle de constitutionalité. Utilizando esta nueva herramienta, el Consejo fue requerido el 16 de noviembre de 2010 por la Primera Cámara Civil de la Corte de Casación, a fin de declarar la conformidad de los artículos 75 y 144 del Código civil con la Constitución, resolviendo en su decisión $\mathrm{N}^{\circ} 2010-92$ que la prohibición del matrimonio entre personas del mismo sexo no contraviene ni la libertad de contraer matrimonio, ni el derecho de llevar una vida familiar normal, ni el principio de igualdad ante la ley. En este sentido, el Consejo, después de afirmar la competencia del legislador para regular el matrimonio, de acuerdo a lo dispuesto en el artículo 34 de la Constitución, se encarga de establecer una marcada diferencia entre los poderes de apreciación y de decisión que tiene el legislador en el desarrollo de sus funciones, frente a la más limitada competencia que tiene el propio Consejo para realizar un control de la conformidad de una determinada disposición legislativa con los derechos y libertades que la Constitución garantiza, para sobre esta base resolver en su considerando $9^{\circ}$ que:

"9. Considerando, por otra parte, que el artículo 6 de la Declaración de 1789 dispone que la ley 'debe ser la misma para todos, sea que proteja, sea que sancione'; que el principio de igualdad no se opone, ni a que el legislador regule de una manera diferente situaciones diferentes, ni a que derogue la igualdad por razones de interés general

del mismo sexo están comprendidas en la protección que confiere el derecho de llevar una vida familiar reconocido por el artículo 8 del Convenio, esta garantía no es violada por la prohibición de acceso al matrimonio a las parejas homosexuales presente en numerosas legislaciones nacionales, considerando que, si bien la institución del matrimonio ha experimentado grandes transformaciones por la evolución de la sociedad desde la adopción del Convenio, hoy en día no existe un consenso europeo sobre esta cuestión, situación que impide a la Corte de imponer una visión determinada sobre esta materia controvertida. Sentencia de la Corte Europea de Derechos Humanos (2010): Caso Schalk y Köpf contra Austria.

Revista de Ciencias Sociales - Número 64 (2014) - Universidad de Valparáíso - ISSN 0716-7725-Valparaíso, Chile 
siempre que, en uno y otro caso, la diferencia de tratamiento que resulte esté en relación directa con el objeto de la ley que se establece; ahora, en lo que concierne al principio según el cual el matrimonio es la unión de un hombre y de una mujer, el legislador ha, en el ejercicio de la competencia que le atribuye el artículo 34 de la Constitución, estimado que la diferencia de situación de las parejas del mismo sexo y las parejas compuestas de un hombre y de una mujer puede justificar una diferencia de tratamiento en cuanto a las reglas del Derecho de la familia; que no concierne al Consejo constitucional substituir su apreciación a aquella del legislador tomando en cuenta, en esta materia, esta diferencia de situación; que, por consiguiente, la queja fundada en la violación del artículo 6 de la Declaración de 1789 debe ser descartada"63.

Como se puede apreciar, en la decisión del Consejo subyace un profundo respeto por el principio democrático, que lo lleva a afirmar la primacía del legislador para definir las condiciones para contraer matrimonio, ejerciendo un poder de apreciación, sin que pueda considerarse que el principio de la libertad de matrimonio le imponga una prohibición al momento de definir cuáles serán sus condiciones, siempre que éstas no sean contrarias a las restantes exigencias constitucionales. De esta manera, según lo afirmado por el Consejo, corresponde al legislador ponderar los intereses involucrados en la definición sobre quiénes pueden contraer matrimonio, pudiendo o no incluir como condición la diferencia de sexos entre los contrayentes, debiendo en consecuencia tener lugar esta discusión en el Parlamento, por vía de una modificación legal al Código civil.

En este contexto, no es de extrañar que la apertura del matrimonio a las parejas del mismo sexo pasara desde la discusión académica y judicial al debate político: en el contexto de las elecciones presidenciales y legislativas de 2012, el entonces candidato a la presidencia de la república, el socialista François Hollande, se comprometió a presentar un proyecto de ley con este fin, promesa que

63. Decisión del Consejo Constitucional (2011): $\mathrm{N}^{\circ} 2010-92$, de 28 de enero de 2011.

Facultad de Derecho y Ciencias Sociales - Universidad de Valparaíso - Chile 
cumpliría el día 7 de noviembre de $2012^{64}$. A pesar de las fuertes oposiciones que generó el proyecto en la doctrina ${ }^{65}$, la división social que se produjo entre sus partidarios y sus detractores ${ }^{66}$, y los arduos debates parlamentarios, la tramitación total del proyecto no tomaría más de 6 meses entre su presentación y su promulgación: el proyecto será aprobado en su primera lectura por la Asamblea nacional el 12 de febrero de 2012, por 329 votos contra 229; el 12 de abril de 2013 será aprobado por el Senado, en su primera lectura, por 170 votos contra 165; para ser finalmente adoptado por la Asamblea el 23 de abril de 2013, por 331 votos contra 225.

64. Sin embargo, debe destacarse que éste no ha sido el primer proyecto presentado con ese fin. Bajo la presidencia de Nicolás Sarkozy, una primera moción apoyada por el conjunto de los parlamentarios de izquierda fue presentada, siendo rápidamente rechazada por la Asamblea nacional el 14 de junio de 2011, por 222 votos a favor y 293 en contra.

65. Por ejemplo, el profesor Fulchiron escribió un artículo denunciando que la aprobación del proyecto importaba una redefinición del matrimonio y un cambio completo en el Derecho de la familia. Según señaló el autor citado "El proyecto de ley que abre el matrimonio y la adopción a las parejas del mismo sexo tiene profundas repercusiones sobre el conjunto del Derecho de la familia. Consagrando una nueva definición de matrimonio, concebido como un simple estatuto de pareja (deja, paradojalmente, a 'refamiliarizarlo' incorporándole la adopción por los cónyuges del mismo sexo), conduce a repensar la articulación del matrimonio con los otros modos de conyugalidad. En cuanto a la consagración de una doble paternidad monosexual en el marco de una filiación desexualizada, incluso de una procreación desexualizada, exige una refundación global del derecho de la filiación carnal y de la adopción". FULCHIRON, Hugues: "La reconnaissance de la famille homosexuelle: étude d'impact”, En: Recueil Dalloz, 2013, $\mathrm{N}^{\circ}$ 2, Págs. 100-106. Disponible en línea en: http://www.dalloz.fr/documentation/ Document?id=ACTU0157049\&ctxt=0_YSR0MT1odWd1ZXMgZnVsY2hpcm9uwqd4 JHNmPXBhZ2UtcmVjaGVyY2hl\&ctxtl=0_cyRwYWdlTnVtPTHCp3MkdHJpZ GF0ZT1GYWxzZcKncyRzbE5iUGFnPTIwwqdzJGlzYWJvPVRydWXCp3Mkb25nbGV0 PQ\%3d\%3d\#TargetSgmlIdACTU0157049 [Fecha última consulta 28 de abril de 2014].

66. Cuestión que se reflejaría de una manera activa, en las multitudinarias

manifestaciones pour y contre la ley, que llegaron a congregar a centenares de miles de personas y que tuvieron lugar en las principales ciudades del país, sobre todo en los primeros meses de 2013.

Revista de Ciencias Sociales - Número 64 (2014) - Universidad de Valparáíso - ISSN 0716-7725-Valparáiso, Chile 
Sin embargo, al igual como había ocurrido con el pacs, antes de la promulgación de la ley el Consejo Constitucional fue requerido en las condiciones previstas en el artículo 61 inciso $2^{\circ}$ de la Constitución, de manera simultánea por un grupo de 60 diputados y de 60 senadores, a fin de revisar la conformidad del texto de la ley de matrimonio para todos con la Constitución. En lo que concierne propiamente a la redefinición de matrimonio contenida en el nuevo artículo 143 del Código civil, los diputados requirentes consideraron que la apertura del matrimonio a las parejas del mismo sexo desconocía un principio fundamental reconocido por las leyes de la República, según el cual el matrimonio es la unión de un hombre y de una mujer, en tanto que, por su parte, los senadores requirentes hicieron igualmente valer que por su carácter fundamental, la definición del matrimonio corresponde a la competencia del constituyente; que el matrimonio entre personas del mismo sexo desconocía las raíces fundamentales del Derecho civil, según la cual la alteridad sexual es el fundamento del matrimonio; que la apertura del matrimonio a las parejas del mismo sexo desviaría la institución del matrimonio a fines que le son completamente ajenos; y en fin, que la importancia del cambio operado por las disposiciones impugnadas en la definición de matrimonio afectarían la libertad de matrimonio y el derecho a mantener las convenciones legalmente celebradas, desde la perspectiva de las personas actualmente casadas.

En su decisión 2013-669 el Consejo Constitucional rechazó el requerimiento, afirmando en su considerando $21^{\circ}$ que el solo hecho que la legislación, hasta la fecha de la ley controlada, haya visto el matrimonio como la unión de un hombre y de una mujer no crea una regla que interese a los derechos y las libertades fundamentales, ni a la soberanía nacional, ni a la organización de los poderes públicos, de manera que no puede constituir un principio fundamental reconocido por las leyes de la República en el sentido del inciso primero del Preámbulo de la Constitución de 1946, debiendo también rechazarse el requerimiento en lo que concierne a que el matrimonio sería "naturalmente" la unión de un hombre y de una mujer; para luego afirmar en su considerando $22^{\circ}$, de una manera plenamente coherente con lo resuelto en la decisión 2010-92, que no corresponde al Consejo sustituirse en la apreciación que realiza el legislador en orden a que, en

Facultad de Derecho y Ciencias Sociales - Universidad de Valparaíso - Chile 
la actualidad, las diferencias que podrían existir entre las parejas de distinto y del mismo sexo no justifican privar a estas últimas del estatus y la protección jurídica vinculados al matrimonio ${ }^{67}$.

Después del rechazo del Consejo Constitucional, el proyecto será promulgado el día 17 de mayo de 2013 por el presidente Hollande (Ley $\mathrm{N}^{\circ}$ 2013-404 de 17 mayo de 2013, que abre el matrimonio a las parejas del mismo sexo) y el primer matrimonio homosexual fue celebrado en Montpellier, el 29 de mayo de 2013. En lo que concierne propiamente al matrimonio (la ley también reforma el régimen de la adopción), la ley establece un nuevo artículo 143 del Código civil, según el cual " $E l$ matrimonio es celebrado entre dos personas de sexo diferente o del mismo sexo", a la vez que modifica los artículos 144, 162, 163 y 164 del Código, a fin de emplear un lenguaje neutro desde la perspectiva del sexo los cónyuges. De manera adicional, más plenamente concordante con los fundamentos de la reforma introducida, se modificó el artículo 165 del Código, con el objeto de introducir la afirmación del carácter republicano de la celebración del matrimonio. Finalmente, se introdujo dos nuevos artículos (201-1 y 202-1 Código Civil) a fin de simplificar las reglas internacionales de conflictos de leyes.

\section{Conclusión}

Como se ha expuesto, el Derecho de la familia francés ha experimentado grandes transformaciones, sobre todo a partir de la segunda mitad del siglo XX, las cuales han tenido por finalidad central asegurar una mayor igualdad entre los géneros y permitir una apertura a las nuevas realidades familiares que disfrutaban de una validación social. En este contexto, debe destacarse que la demanda de igualdad comenzó por transformar la forma como son concebidas las relaciones entre marido y mujer en el matrimonio, cuestión que obligó al legislador a introducir las reformas necesarias destinadas a terminar con la preeminencia del hombre en el marco de esta relación. Por otra parte, los cambios sociales han exigido un reconocimiento de los otros modelos 67. Decisión del Consejo Constitucional (2013): N²013-669, de 17 de mayo de
2013.

Revista de Ciencias Sociales - Número 64 (2014) - Universidad de Valparáíso - ISSN 0716-7725-Valparáiso, Chile 
familiares, que no se encuentran fundados en la alianza matrimonial. Por esta razón, el legislador ha debido cesar en su pretensión de establecer un modelo exclusivo de regulación de la vida en común (el matrimonio) incorporando progresivamente otras formas de hacer familia, que contaron con una creciente validación social, como ocurrió con el creciente número de derechos asociados al concubinato en un primer momento, y luego con la creación de un nuevo estatuto de pareja dotado de identidad propia y una legitimidad independiente del matrimonio, como ocurrió con el pacs.

En el contexto de este proceso de transformaciones, uno de los grupos más favorecidos han sido las personas homosexuales, quienes han obtenido un lugar en el Derecho de la familia para el reconocimiento y la protección de sus proyectos de vida en pareja. Para poder constatar el alcance de esta evolución, se debe considerar que su punto de partida fue el espacio de "no Derecho", la absoluta ignorancia de sus relaciones por parte del orden jurídico, cuando no derechamente su penalización, como ocurrió con ciertas conductas a partir de las regulaciones de Vichy, y que a partir de este punto, y gracias a un proceso continuo de visibilización de sus demandas, iniciado en los años setenta y en gran parte acelerado en los años ochenta a causa de las dramáticas consecuencias de la epidemia del SIDA, han obtenido una plena validación pública por medio de sucesivas reformas legislativas ${ }^{68}$, expresada hoy en la plena posibilidad que tienen de acceder a todas las instituciones propias del Derecho de la familia, en las mismas condiciones que las parejas heterosexuales. Como ha dicho Borrillo, evocando al sociólogo Eric Fassin:

"la democracia sexual parece estar definitivamente en marcha. Las discriminaciones sexistas y homofóbicas son sancionadas por la ley, la unión entre personas del mismo sexo es reconocida y la mejora de la posición de las mujeres en la vida política (paridad) constituye un objetivo común al conjunto de las fuerzas políticas francesas. En lo

68. Resultando especialmente destacable la ausencia de toda respuesta a sus demandas por parte de la jurisprudencia civil y constitucional, como se ha podido ver en este trabajo.

Facultad de Derecho y Ciencias Sociales - Universidad de Valparaíso - Chile 
que concierne a los homosexuales, incluso la derecha, en otra época hostil a las uniones homosexuales, no solamente ha aceptado el pacs, sino que no ha cesado de mejorarlo, acercándolo al matrimonio. Por añadidura ella ha reforzado el dispositivo antidiscriminatorio en materia de orientación sexual. Desde este punto de vista, uno no puede sino estar de acuerdo con el sociólogo: en materia de igualdad, la democratización sexual parece evidente" ${ }^{\prime 9}$.

En este contexto, se puede pensar que la apertura del matrimonio a las parejas del mismo sexo no es sino la medida más reciente destinada a profundizar la igualdad entre todos los ciudadanos.

\section{Bibliografía}

BACH-IGNASSE, Gérard: "Familles et homosexualités". En: Borrillo, Daniel. Homosexualités et droit. De la tolérance sociale à la reconnaissance juridique. París: PUF, 1998, págs. 122-138.

BASDEVANT-GAUDEMET, Brigitte y GAUDEMET, Jean: Introduction historique au Droit XIII ${ }^{e}-X X^{e}$ Siècles. París: L.G.D.J., 2000.

BÉNABENT, Albert: Droit civil de la famille. $11^{\circ}$ edición. París: Litec, 2003.

BORRILLO, Daniel: "Who Is Breaking With Tradition? The Legal Recognition of Same-Sex Partnership in France and the Question of Modernity”. En: Yale Journal of Law and Feminism, 89, 2005, págs. 8997.

BORRILLO, Daniel: Le Droit des sexualités. París: PUF, 2009.

CABALLERO, François: Droit du sexe. París: L.D.G.J., 2010.

CABRILLAC, Rémy: Introduction générale au Droit. $7^{\circ}$ edición. París: Dalloz, 2007.

CHAINE NOTARIALE DE RECHERCHES ET D'APPLICATIONS EN DROIT DES AFFAIRES: Les contrats entre époux, parents et concubins. Aspects juridiques et fiscaux. París: Litec, 1984.

69. BORRILlO, Daniel (2009): Ob. cit. Pág. 33. 
COING, Helmut: Derecho privado europeo. Derecho común más antiguo. (1500-1800). Tomo I. Madrid: Fundación Cultural del Notariado, 1996.

CORNU, Gérard: Vocabulaire juridique. $8^{\circ}$ edición. París: PUF, 2007. COURTRAY, François: "Pacte civil de solidarité: une occasion manqué".

En: Revue de Droit sanitaire et social, 2000, N 1, enero-marzo, Págs. 1-32. Disponible en línea en: http://www.dalloz.fr/documentation/ Document? id $=$ RDSS $\% 2 \mathrm{fCHRON} \% 2 \mathrm{f} 2000 \% 2 \mathrm{f0001} \& \mathrm{ctxt}=0 \_$YSR0M T1jb3VydHJhecKneCRzZj1wYWdILXJIY2hlcmNoZQ\%3d\%3d\&ctxtl= 0_cyRwYWdITnVtPTHCp3MkdHJpZGF0ZT1GYWxzZcKncyRzbE5iUG FnPTIwwqdzJGlzYWJvPVRydWXCp3Mkb25nbGV0PQ\%3d\%3d\# TargetSgmlIdRDSS/CHRON/2000/0001 [Fecha última consulta 28 de abril de 2014].

FULCHIRON, Hugues: "La reconnaissance de la famille homosexuelle: étude d'impact”, En: Recueil Dalloz, 2013, º 2, págs. 100-106.

Disponible en línea en: http://www.dalloz.fr/documentation/ Document?id $=$ ACTU0157049\&ctxt=0_YSR0MTlodWd1ZXMgZnVsY2hpc m9uwqd4JHNmPXBhZ2UtcmVjaGVyY2hl\&ctxtl=0_cyRwYWdlTnVtPTHC p3MkdHJpZGF0ZT1GYWxzZcKncyRzbE5iUGFnPTIwwqdzJGlzYWJvPV RydWXCp3Mkb25nbGV0PQ\%3d\%3d\# TargetSgmlIdACTU0157049 [Fecha última consulta 28 de abril de 2014].

GAUDEMET, Jean: "Sociétés et mariage". En: Gaudemet, Jean. Sociétés et mariage. Estrasburgo: Cerdic-Publications, 1980.

GODARD, Joëlle: "PaCS Seven Years On: Is It Moving Towards Marriage?" En: International Journal of Law, Policy and the Family, 2007, N² 21, págs. 310-321.

GRIMALDI, Michel: "El pacto civil de solidaridad en el Derecho francés". En: Revista Chilena de Derecho Privado, Fundación Fernando Fueyo, 2004, Nº 3, págs. 69-84.

HAUSER, Jean y RENCHON, Jean-Louis (directores): Le statut juridique de la couple marié et de la couple non marié en Droit belge et français. Bruselas: Larcier, 2012.

INSTITUT NATIONALE DE LA STATISTIQUE ET DES ÉTUDES ECONOMIQUES (INSEE), Statistiques sur l'évolution du nombre de mariages et de pacs conclus jusqu'en 2012. Disponible en línea en: http://www.insee.fr/fr/themes/tableau.asp? ref_id=NATTEF02327 [Fecha última consulta 28 de abril de 2014].

Facultad de Derecho y Ciencias Sociales - Universidad de Valparaíso - Chile 
MALAURIE, Philippe y FULCHIRON, Hugues: La famille. $3^{\circ}$ edición. París: Defrénois, 2009.

PATERNOTTE, David: "Matrimonio 'homosexual' y ciudadanía: hipótesis de la resignificación”. En: Nomadías, 2009, Nº 10.

PILLEBOUT, Jean François: Le PACS. Pacte civil de solidarité. París: Litec, 2002.

TERRÉ, François y FENOUILLET, Dominique: Droit civil. La famille. $8^{\circ}$ edición. París: Dalloz, 2011.

THÉRY, Irene: Couple, filiation et parenté aujourd'hui. Le droit aux mutations de la famille et de la vie privé. París: Editions Odile Jacob, 1998.

VIVIER, Jean-Loup: Le pacte civil de solidarité. Un nouveau contrat. París: L'Harmattan, 2001.

\section{JURISPRUDENCIA}

Decisión del Consejo Constitucional: $\mathrm{N}^{\circ}$ 99-419, de 9 de noviembre de 1999. Disponible en línea en el sitio web: http:// www.legifrance.gouv.fr/affichJuriConst.do? oldAction $=$ rechJuriConst\&idTexte $=$ CONSTEXT000017667969 $\&$ fastReqId $=$ 1803865896\&fastPos $=1$ [Fecha última consulta 28 de abril de 2014].

Decisión del Consejo Constitucional: $\mathrm{N}^{\circ}$ 2010-92, de 28 de enero de 2011. Disponible en línea en el sitio web: http://www. legifrance.gouv.fr/affichJuriConst.do?oldAction $=$ rechJuriConst\&idTexte $=$ CONSTEXT000023603680\&fastReqId $=$ 1534064732\&fastPos $=1$ [Fecha última consulta 28 de abril de 2014].

Decisión del Consejo Constitucional: N²013-669, de 17 de mayo de 2013. Disponible en línea en el sitio web: http://www. legifrance. gouv.fr/affichJuriConst.do ?oldAction $=$ rechJuriConst\&idTexte $=$ CONSTEXT000027415593\&fastReqId $=1326932302 \&$ fastPos $=2$ [Fecha última consulta 28 de abril de 2014].

Sentencia de la Corte Europea de Derechos Humanos: Caso Schalk y Köpf contra Austria de 24 de junio de 2010, Demanda $N^{\circ} 30141 /$ 04. Disponible en el sitio web: http://hudoc.echr.coe.int/sites/fra/pages/ search.aspx?i=001-99643\# \{\%22itemid\%22:[\%22001-99643\%22]\} [Fecha última consulta 28 de abril de 2014]. 
Decisión de la Cámara Social de la Corte de Casación: N 86-10.665 de

11 de julio de 1989. Disponible en línea en el sitio web: http:// www.legifrance.gouv.fr/affichJuriJudi.do? oldAction $=$ rechJuriJudi\&idTexte $=$ JURITEXT000007022234\& fastReqId $=$ 956248249\&fastPos $=1$ [Fecha última consulta 28 de abril de 2014]. Decisión de la Tercera Cámara Civil de la Corte de Casación: $N^{\circ} 95-$

20.779, de 17 de diciembre de 1997. Disponible en línea en el sitio web: http://www.legifrance.gouv.fr/affichJuriJudi.do?oldAction $=$ rechJuriJudi\&idTexte $=$ JURITEXT000007039208\&fastReqId $=1802157304 \&$ fastPos $=1$ [Fecha última consulta 28 de abril de 2014].

Decisión de la Primera Cámara Civil de la Corte de Casación: $N^{\circ} 05-$ 16.627, de 13 de marzo de 2007. Disponible en línea en el sitio web: http://www.legifrance.gouv.fr/affichJuriJudi.do?oldAction $=$ rechJuriJudi\&idTexte $=$ JURITEXT000017826334\&fastReqId $=1050329939 \&$ fastPos $=1$ [Fecha última consulta 28 de abril de 2014]. 